\title{
Toxicity of atmospheric particulate matter using aquatic bioassays
}

\author{
C. Papadimitriou ${ }^{1}$, V. Evagelopoulos ${ }^{2}$, P. Samaras ${ }^{1}$,
} A. G. Triantafyllou 2 , S. Zoras ${ }^{2} \&$ T. A. Albanis ${ }^{3}$

${ }^{1}$ Department of Pollution Control Technologies, Technological Educational Institute of W. Macedonia, Kozani, Greece ${ }^{2}$ Department of Geotechnology and Environmental Engineering, Laboratory of Atmospheric Pollution and Environmental Physics, Technological Educational Institute of W. Macedonia, Kozani, Greece ${ }^{3}$ Department of Chemistry, University of Ioannina, Panepistimioupolis, Ioannina, Greece

\begin{abstract}
The investigation of ecotoxicological effects of particulate matter and the increasing interest in correlating chemical composition to biological impacts is of paramount importance. A complete assessment of biological impacts will require a broad look at the effects of human health and the terrestrial and aquatic environments. The objective of this work was to assess the effects of various sizes of particulates on aquatic organisms. Samples were collected from filters and the filter contents were extracted with DCM using a Soxhlet extractor. Then concentration DCM extracts were condensated to $2 \mathrm{ml}$ by rotary evaporation and each millilitre of extract was exchanged with $1 \mathrm{ml}$ of DMSO and then diluted to freshwater. The samples were then analyzed for their ecotoxicological properties with Vibrio fischeri and bioassay. Five consecutive dilutions of the sample were tested in order to determine the EC50 values as a result of different size of particulates.
\end{abstract}

Keywords: PM10, PM2.5, particulates, toxicity, bioassays.

\section{Introduction}

The knowledge of the distribution of airborne particulate matter (PM) into size fractions has become an increasing area of focus during the examination of the 
effects of particulate pollution. Particle size distribution is important for human exposure and risk assessment, as well as for understanding the mechanisms of atmospheric processes [1]. Several studies have shown correlation between respiratory symptoms and heart diseases with the inhalable particles [2, 3]. Particles with a size less than $10 \mathrm{~mm}$ (PM10) have long been implicated in causing adverse health effects and increased mortality [4] whereas fine (PM2.5) and ultrafine particles impose even higher risk [5-7]. Thus, it is of paramount importance the ability to correlate the sources and chemical composition of aerosols with their biological impact. Complete assessment of the biological impact of aerosols would require a broad look at the effects on human health and the terrestrial and aquatic environments. Several analytical methods have been developed for the determination of the detailed chemical composition of atmospheric aerosol (gas chromatography coupled with mass spectroscopy GCMS, inductively coupled plasma ICP mass spectroscopy, X-ray fluorescence, etc) [13]. These techniques have been used to demonstrate the extreme diversity of the composition of atmospheric aerosols as a function of temporal and spatial factors. Similarly, biological characterization of atmospheric and emission source particulates has been conducted on a variety of species, with rodent inhalation studies $[14,15]$ and bacterial assays [16-19] representing the bulk of the in vivo research. In addition, in vitro work with human and rat cell lines has further expanded the collective knowledge of the biological response mechanisms to particulates [20-22]. However, due to the complex nature of analytical monitoring and especially of biological indicators, a limited number of studies have presented potential correlations of chemical parameters and biological characteristics, focusing mainly on bulk or physical characterization (elemental and organic carbon, inorganic elements, particle size, etc.).

The area of Kozani - Ptolemais Basin (KPB) is a heavy industrialized area in the north-western part of Greece, which is characterized by a complex topography. Within the basin, four lignite thermal power stations (PS) are operated by the Greek Public Power Corporation (GPPC) with a total installed power capacity of more than $4 \mathrm{GW}$. These power stations contribute to about $70 \%$ of the total electrical energy produced in Greece. The lignite that is combusted in the power stations is mined in the nearby open-pit mines. Sulphur content in feedstock is low $(<1 \%)$; in addition the high content of calcium oxides in the mineral matter of the raw lignite contributes to negligible releases of sulphur oxides in the flue gases. Thus, dust emissions seem to be the most significant air pollution problem in the area; the measured ambient concentrations of suspended particles are often at high levels exceeding local and international standards $[4,5]$. The high particulate concentration in this area has been attributed to two parameters: (a) particulates released in the flue gases of the thermal power stations. The required amount of lignite for the operation of one $1200 \mathrm{MW}$ power station is estimated to about 54000 tons per day. About $15 \%$ of raw fuel is transformed to ash, corresponding to about 8100 tons of ash produced per day. Electrostatic precipitators have been installed in the power stations, aiming to the removal of fly ash from flue gases; an optimum removal capacity of about $99.9 \%$ results to about 8.5 tones of fly ash emitted per day in 
the atmosphere as primary suspended particulate pollutants; (b) another significant source of inhalable particulates is the dust generated from mining operations, including excavation, transportation by uncovered trucks, deposition of lignite and ash and potential subsequent re-suspension due to air currents. Monitoring of air quality in the area has started in 1983 by the installation and operation of a network of sampling stations that has been upgraded in 1997. However the ecotoxicological effects of the particulate matter have not been investigated, in order to assess the environmental impact associated to the particulate matter.

The aim of this work was the evaluation of the ecotoxic properties of particulates emitted in a highly industrialized area, the assessment of potential parameters affecting the toxicity and the correlation to sampling conditions.

\section{Materials and methods}

\subsection{Sample collection}

Size-segregated particulate samples (PM10 and PM2.5) were collected in the industrial area of the opencast mines at the village Klitos and the urban area of Kozani in north-western Greece (Figure 1), for a period of three months (January to March). The samples were collected by Andersen Reference Ambient Air Sampler (RAAS), and dichotomous sampler with a PM10 inlet probe for the collection of particles in the PM2.5 and PM10 size range for gravimetric analysis. The samples were collected by passing air through a $37 \mathrm{~mm}$ PTFE filter. The technique for monitoring the size distribution of airborne aerosols with a dichotomous sampler was based on inertial impaction of particles into a void (virtual surface). The total flow and the coarse particle flow were adjusted by the use of certain rotameters on the sampler.

RAAS PM2.5/10 Sequential Filter Sampler System specifically designed to comply with requirements of the National Ambient Air Quality Standards (NAAQS) for Particulate Matter (40 CFR Part 50). According to the new standard a fixed flow rate sampler is required, operating at 16.67 liters/minute (one cubic meter per hour), using a specified inlet, tubing, secondary size selective impactor, and filter holder. The inlet should be a 10-micrometer (nominal) cut-point providing wind speed and direction independent sampling to remove particles larger than $10 \mu \mathrm{m}$. The connecting tubing was a 12 -inch length anodized aluminum tubing with a precisely specified inner diameter and surface finish. The secondary size selective element was the WINS impactor that further reduced the passed particulate to exclude particles larger than $2.5 \mu \mathrm{m}$. The particulates were then collected on a $47 \mathrm{~mm}$ PTFE filter.

Before sampling, the filter was equilibrated to constant temperature and relative humidity conditions and weighed. After sampling, the filter was equilibrated to the constant temperature and humidity conditions and weighed. The concentration was calculated by dividing the weight of the particulates captured on the filter by the volume of air (at ambient conditions) that passed 
through the sampler. The flow rate was required to be maintained within $5 \%$ of 16.67 liters per minute with a coefficient of variation less than $2 \%$.

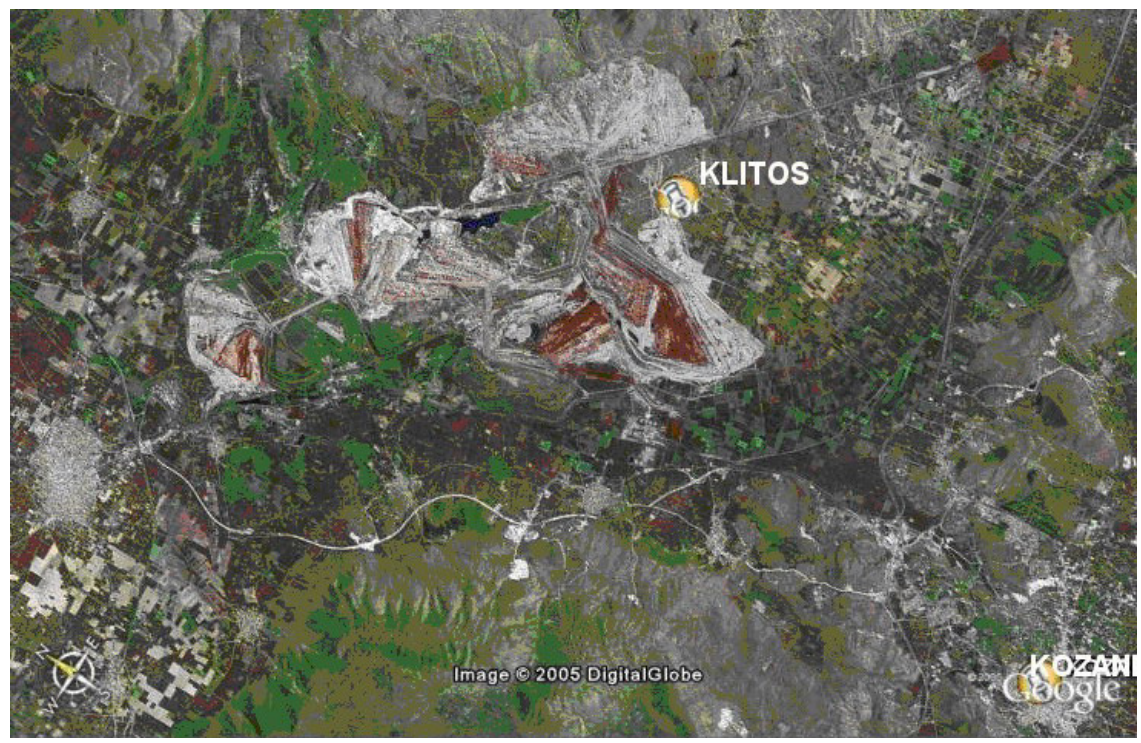

Figure 1: $\quad$ Map of the sampling area [20].

\subsection{Treatment of samples}

Each filter was Soxhlet extracted in $300 \mathrm{ml}$ dichloromethane (DCM, provided by Merck) followed by rotary evaporation to $1 \mathrm{ml}$. The concentrated extract was then exchanged with $1 \mathrm{ml}$ dimethylsulfoxide (DMSO) and diluted to $300 \mathrm{ml}$ with deionised water. Toxicity testing was performed using various dilutions of the final sample volume of $300 \mathrm{ml}$, that were prepared by the appropriate amounts of deionised water.

\subsection{Toxicity Testing with Vibrio fischeri}

Toxicity testing included the measurement of bioluminescence inhibition of the marine bacteria Vibrio fischeri within a short exposure time. The bacteria were in freeze-dried form and were activated prior to the use. The salinity of the samples was adjusted with the addition of a $2 \% \mathrm{NaCl}$ solution. The light emitted from a control sample and the various samples were measured after exposure of the bacteria to the sample at certain times, 5-15 and $30 \mathrm{~min}$, by the Microtox model 500 analyzer (Azur Environmental) (Microtox Manual, 1998). The percentage bioluminescence inhibition and the $\mathrm{EC}_{50}$ value (the percentage of sample concentration that causes $50 \%$ effect on the test organism) of each sample were calculated as an end point. 


\section{Results and discussion}

During the sampling period, 12 samples were collected from the sampling point of Kozani, including six filters of fine particulates and 6 filters of coarse particulates, while 6 samples were collected from Klitos sampling point corresponding to 3 filters of PM 10 and 3 of PM2.5. Sample symbols and the corresponding collection dates are given in Table 1.

Table 1: Sample symbols and the corresponding sampling dates for the toxicity assessment of particulates.

\begin{tabular}{|c|c|c|c|}
\hline \multicolumn{2}{|c|}{ Kozani } & \multicolumn{2}{c|}{ Klitos } \\
\hline Symbol & Date & Symbol & Date \\
\hline $\mathrm{A}_{1}$ & $6 / 1 / 2006$ & $\mathrm{~B}_{1}$ & $6 / 1 / 2006$ \\
\hline $\mathrm{A}_{2}$ & $14 / 1 / 2006$ & $\mathrm{~B}_{2}$ & $2 / 2 / 2006$ \\
\hline $\mathrm{A}_{3}$ & $2 / 2 / 2006$ & $\mathrm{~B}_{3}$ & $18 / 3 / 2006$ \\
\hline $\mathrm{A}_{4}$ & $27 / 2 / 2006$ & & \\
\hline $\mathrm{A}_{5}$ & $15 / 3 / 2006$ & & \\
\hline $\mathrm{A}_{6}$ & $18 / 3 / 2006$ & & \\
\hline
\end{tabular}

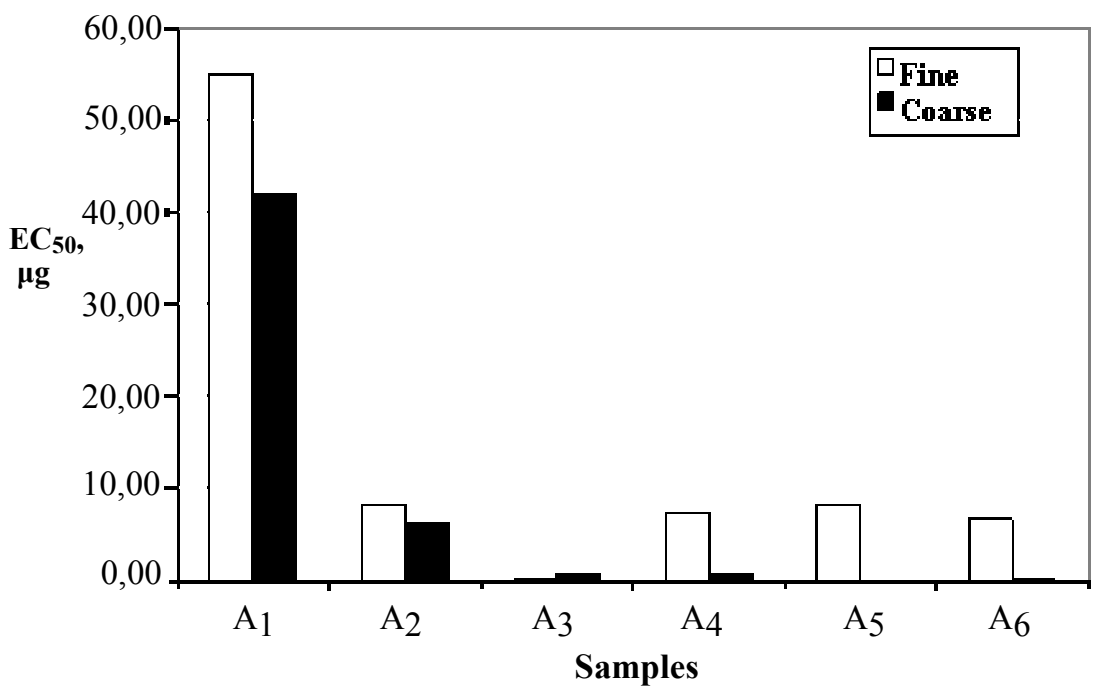

Figure 2: $\quad \mathrm{EC}_{50}$ values for the fine and coarse particulate matter collected from Kozani sampling site.

The $\mathrm{EC}_{50}$ values obtained from the toxicity testing of the particulate matter collected from Kozani and Klitos sampling points are shown in Figures 2 and 3, respectively. 
$\mathrm{EC}_{50}$ values of samples collected from the Kozani sampling point were ranging from 0 to $55 \mu \mathrm{g}$. Coarse particulates exhibited $\mathrm{EC}_{50}$ concentrations ranging from 0 to $42 \mu \mathrm{g}$, while the respective concentrations for fine particulates were ranging from 8 to $55 \mu \mathrm{g}$. In general, coarse particulates exhibited increased toxic effects to Vibrio fischeri, and the $\mathrm{EC}_{50}$ values were lower that those of the fine particulate matter.

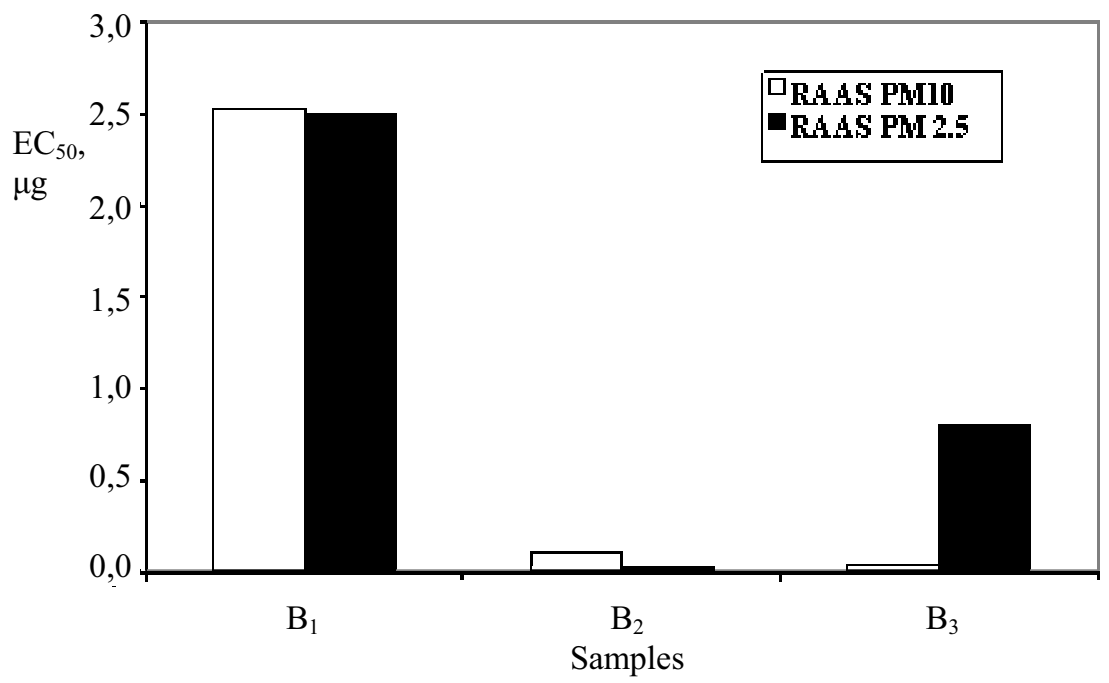

Figure 3: $\quad \mathrm{EC}_{50}$ values for PM 10 and PM 2.5 collected from Klitos sampling site.

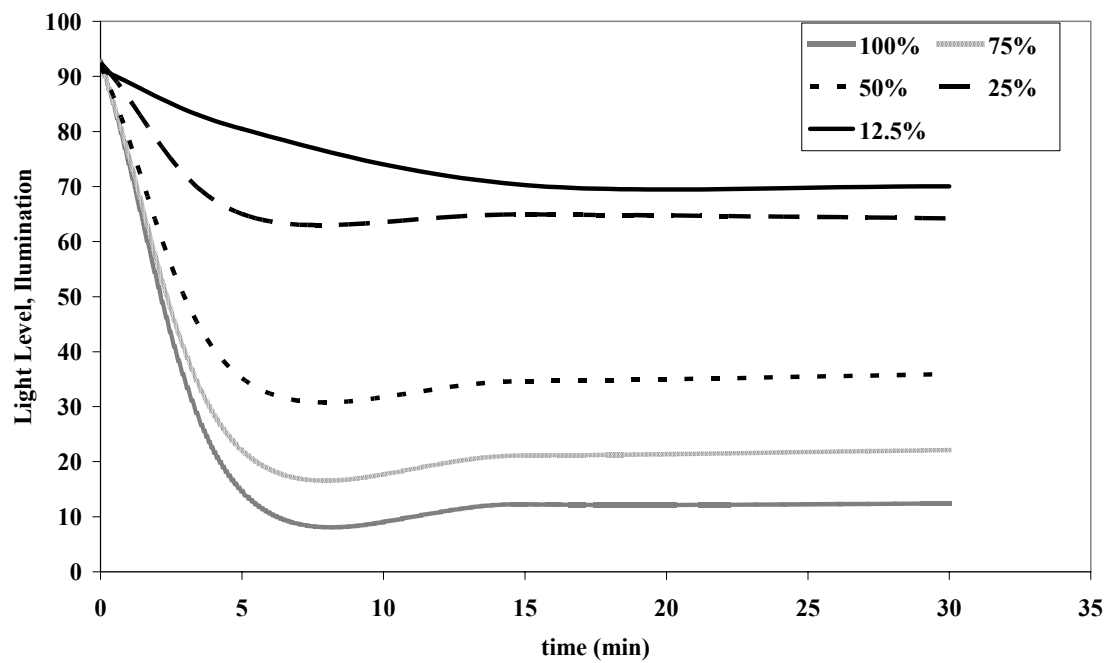

Figure 4: Representative Light Level-Time response curves for various dilutions of sample A2. 
$\mathrm{EC}_{50}$ values of samples collected from Klitos sampling site were ranging from 0 to $2.5 \mu \mathrm{g}$ for both PM10 and PM 2.5 samples. PM2.5 samples exhibited higher toxicity to Vibrio fischeri than PM10 samples. The $\mathrm{EC}_{50}$ values found for Klitos were lower that those of Kozani, suggesting differences in the physical and chemical characteristics of particulate matter.

For all samples, the light - level response curves presenting the relation of the exposure time of the organisms to the various dilutions of samples were investigated, in order to evaluate potential factors responsible for the toxicity of the samples. Typical light response curves from various dilutions of a representative sample are shown in Figure 4; all samples presented almost similar response curves.

As shown in this figure, a sharp decrease of emitted bioluminescence was observed within $5 \mathrm{~min}$ of exposure, and remained almost constant at higher contact times. In addition, the higher the concentration of the sample extract, the higher was the initial decrease of bioluminescence. This pattern of light - level response curve is typical of samples containing mainly organic compounds.

Ambient samples may be used for the investigation of the effect of pollutants on specific organisms, by using bioassay techniques. However, the estimation of potential factors responsible for the observed toxicity is a complicated process, as several parameters may affect the response of test species. In the current study, increased toxic properties were observed for samples collected from a rural area (Klitos), than samples collected from an urban one (Kozani). However, as it was mentioned, the work area is an industrial location with significant environmental problems, attributed both to the excavation and transportation of coal resources and to the flue gas releases from the thermal power plants. For the urban area of Kozani, low toxicity effects were observed that could be attributed to sources such as exhaust particulates, gasoline powered vehicles and even biogenic particulates.

\section{Acknowledgement}

This work was funded by the Greek Ministry of Education and Religion Affairs, within the framework of "Archimedes II", enhancement of research activities in Technological Educational Institutes, Project 2.6.1IA, "Study of the adsorption and transport processes from particulate matter to urban and rural areas situated close to coal mines and electricity production power plants".

\section{References}

[1] Fishbein, L. Sources, nature and levels of air pollutants, in: L. Tomatis Ed., Air Pollution and Human Cancer, Monographs, European School of Oncology, Springer-Verlag, New York, 1993, pp. 9-34.

[2] Lewtas, J. Experimental evidence for the carcinogenicity of air pollutants, in: L. Tomatis Ed., Air Pollution and Human Cancer, Monographs, European School of Oncology, Springer-Verlag, New York, 1993, pp. 49-61. 
[3] Triantafyllou, A.G.: 2003, 'Levels and trend of suspended particles around large lignite power stations', Environmental Monitoring and Assessment 89, 15-34.

[4] Triantafyllou, A.G., Zoras, S., Evagelopoulos, V.: 2005, 'Particulate matter over a seven year period in urban and rural areas within, proximal and far from mining and power station operations in Greece, Environmental Monitoring and Assessment, 159-165.

[5] Sasaki, Y. Kawai, T. Ohyama, K.-I. Nakama, A. Endo, R. Carcinogenicity of extract of airborne particles using newborn mice and comparative study of carcinogenic and mutagenic effect of the extract, Arch. Environ. Health 421987 14-18.

[6] Crebelli, R. Fuselli, S. Meneguz, A. Aquilina, G. Conti, L. Leopardi, P. Zijno, A. Baris, F. Carere, A. In vitro and in vivo mutagenicity studies with airborne particulate extracts, Mutat. Res. 2041988 565-575.

[7] Crebelli, R. Fuselli, S. Baldassarri, L. Turrio Ziemacki, G. Carere, A. Benigni, R. Genotoxicity of urban air particulate matter: correlations between mutagenicity data, airborne micropollutants, and meteorological parameters, Int. J. Environ. Health Res. 51995 19-34.

[8] De Raat, W.K. Polycyclic aromatic hydrocarbons and mutagens in ambient air particles, Toxicol. Environ. Chem. 161988 259-279.

[9] Hadnagy, W. Seemayer, N.H. Tommingas, R. Ivanfy, K. Comparative study of sister-chromatid exchanges and chromosomal aberrations induced by airborne particulates from an urban and a highly industrialized location in human lymphocyte cultures, Mutat. Res. 2251989 27-32.

[10] Viras, L.G. Athanasiou, K. Siskos, P.A. Determination of mutagenic activity of airborne particulates and of the benzo $a$ pyrene concentrations in Athens atmosphere, At mos. Environ. B 241990 267-274.

[11] Viras, L.G. Siskos, P.A. Samara, C. Kouimtzis, T. Athanasiou, K. Vavatzandis, A. Polycyclic aromatic hydrocarbons and mutagens in ambient air particles sampled in Thessaloniki, Greece, Atmos. Environ. 10 1991 999-1007.

[12] Fuselli, S. Benigni, R. Conti, L. Carere, A. Crebelli, R.. Volatile organic compounds VOCs and air mutagenicity: results of one year monitoring at an urban site, Int. J. Environ. Health Res. 51995 123-132.

[13] Pagano, P. De Zaiacomo, T. Scarcella, E. Bruni, S. Calamosca, M. Mutagenic activity of total and particle-sized fractions of urban particulate matter, Environ. Sci. Technol. 301996 3512-3516

[14] Kim Oanh, N.T. Upadhyay, N. Zhuang, Y.-H. Hao, Z.-P. Murthy, D.V.S. Lestari, P. Villarin, J.T. Chengchua, K. Co, H.X. Dung, N.T. Lindgren, E.S. 2006 Particulate air pollution in six Asian cities: Spatial and temporal distributions, and associated sources, Atmospheric Environment 40 3367-3380

[15] Pershagen, G. Simonato, L. Epidemiological evidence on air pollution and cancer, in: L. Tomatis Ed. , Air Pollution and Human Cancer, Monographs, European School of Oncology, Springer-Verlag, New York, 1993, pp. 64-74 
[16] Obot, C. J.; et al. A comparison of murine and human alveolar macrophage responses to urban particulate matter. Inhalation Toxicol. 2004, 16 (2), 69-76.

[17] Hannigan, M. P.; et al. Bacterial Mutagenicity of Urban Organic Aerosol Sources in Comparison to Atmospheric Samples. Environ. Sci. Technol. 1994, 28 (12), 2014-2024.

[18] Oanh, N. T. K.; Nghiem, L.; Phyu, Y. L. Emission of polycyclic aromatic hydrocarbons, toxicity, and mutagenicity from domestic cooking using sawdust briquettes, wood, and kerosene. Environ. Sci. Technol. 2002, 36 (5), 833-839.

[19] Pedersen, D. U.; et al. Human-cell mutagens in respirable airborne particles in the Northeastern United States. 1. Mutagenicity of Fractionated Samples. Environ. Sci. Technol. 2004, 38 (3), 682-689.

[20] Google Earth, http://earth.google.com.

[21] B. B. Hicks, R. A. Valigura, F. B Courtright, The role of the atmosphere in coastal ecosystem declines Future research directions. Estuaries, 2000 23 (6), 854-863.

[22] Sheesley, R. J.; et al. , Toxicity of ambient atmospheric particulate matter from the Lake Michigan (USA) airshed to aquatic organisms. Environ. Toxicol. Chem., in press 